\title{
PARKEAR OR NOT PARKEAR, THAT'S THE QUESTION: UM ESTUDO SOBRE AS INOVAÇÕES LEXICAIS REALIZADAS POR IMIGRANTES BRASILEIROS NOS EUA
}

\section{PARKEAR OR NOT PARKEAR, THAT'S THE QUESTION: A STUDY ABOUT THE LEXICAL INNOVATIONS USED BY BRAZILIAN IMMIGRANTS IN THE USA}

\section{Valquiria Carolina Pimentel Sales de Carvalho*}

RESUMO: Este artigo tem como objetivo principal o estudo do falar de brasileiros imigrantes nos Estados Unidos da América. Os brasileiros imigrantes fazem uso de muitas inovações lexicais que parecem aproximar o inglês do português ao falarem uns com os outros nos EUA. Essas inovações apresentam certa regularidade e parecem ser utilizadas por alguns grupos de brasileiros e estigmatizadas por vários. Com base nos postulados variacionistas de Labov, Weinreich e outros, fizemos um estudo etnográfico constituído de entrevistas, questionários e listas de disponibilidade léxica com o objetivo de catalogar, compreender e explicar o uso dessas inovações lexicais.

PALAVRAS-CHAVE: inovações lexicais, variação linguística, fatores sociodemográficos, línguas em contato.

ABSTRACT: This article aims at studying the speech of Brazilian immigrants to the United States of America. The Brazilian immigrants use some lexical innovations which seem to be the result of language contact between Portuguese and English. These innovations have a certain regularity and are used only within the Brazilian community in the USA. Based on the variationist studies of Labov, Weinreich and others, we did an ethnographic study comprising interviews, questionnaires and a lexical availability list.

KEYWORDS: lexical innovations, linguistic variation sociodemographic factors, languages in contact.

\footnotetext{
* Pontifícia Universidade Católica de Minas (PUC-Minas), Belo Horizonte/ MG. Professora de Fonologia de Língua Inglesa, Leitura e Produção de Textos e Inglês Comercial do Departamento de Letras. Email: valquiria. carolina@gmail.com.
} 



\section{PARKEAR OR NOT PARKEAR, THAT'S THE QUESTION: UM ESTUDO SOBRE AS INOVAÇÕES LEXICAIS REALIZADAS POR IMIGRANTES BRASILEIROS NOS EUA}

\section{Introdução}

De acordo com Chambers (1995), quando falamos, revelamos não só as qualidades pessoais e alguma sensibilidade para o contexto social, mas também algumas características que são compartilhadas entre as pessoas que são socialmente ligadas a nós, em termos de posição social, do lugar onde fomos criados e de outros pontos-chave da nossa história de vida. Assim, a linguagem humana parece ser a forma mais transparente de revelarmos a nossa identidade.

A observação de uma peculiaridade linguística resultou no meu interesse em estudar a língua de contato entre os falantes do português do Brasil que vivem e trabalham nos arredores de New York e de Boston. A motivação do meu interesse está em experiências pessoais visitando lugares nos Estados Unidos onde havia uma grande concentração de brasileiros.

Motivada por inquisições a respeito da diversidade entre as línguas e as variações e mudanças sofridas por elas, decidi pesquisar a fala dos imigrantes falantes de português brasileiro nos Estados Unidos, mais especificamente em New Jersey e em Massachussets, onde a maioria deles está concentrada. Os imigrantes brasileiros, principalmente aqueles que vivem ilegalmente em países ricos como Estados Unidos, Canadá e Austrália, são pessoas que 
abandonaram sua terra natal em busca de uma chance de resolverem seus problemas financeiros em países economicamente estáveis. Sabemos que essas pessoas, em geral, desempenham trabalhos braçais, que não requerem qualificação acadêmica, trabalham muitas horas por dia e moram em comunidades brasileiras.

A população brasileira a que me refiro usa um tipo de código que se assemelha tanto ao inglês quanto ao português. Os brasileiros imigrantes fazem uso de muitas inovações lexicais que parecem aproximar o inglês do português ao falarem uns com os outros nos EUA. Essas inovações têm certa regularidade e parecem ser utilizadas pela maioria dos imigrantes brasileiros, mas são, paradoxalmente, estigmatizadas também pela maioria deles.

\section{O imigrante brasileiro nos EUA}

Os trabalhos desempenhados pela maioria dos homens brasileiros nos EUA são na construção civil, como pedreiros e ajudantes de pedreiro; em oficinas mecânicas; como engraxates em prédios de executivos; como cozinheiros e lavadores de pratos em restaurantes; como motoristas; como caixas em lojas e supermercados; e também como pessoal de limpeza de prédios e lojas; além de serviços de pintura em automóveis e imóveis e como "kaddies" (carregadores de bolsas e tacos) em campos de golfe. As mulheres brasileiras trabalham como babysitters = babás de horário integral (também chamadas de nannies); como diaristas; cozinheiras; lavadoras de prato em restaurantes; empregadas domésticas; e como atendentes em salões de beleza. Algumas dessas brasileiras abrem firmas e contratam outras brasileiras em um processo de reinvenção da apropriação da mais valia de suas compatriotas em terras de Tio Sam.

Muitos brasileiros abrem firmas e exploram serviços de pintura em residências e prédios, construção, limpeza de supermercados, conserto e limpeza de sapatos, e empregam outros brasileiros, muitas vezes em situação ilegal. Esses brasileiros não podem, portanto, exigir seus direitos, pois se encontram em situação ilegal no país.

Podemos dizer que os brasileiros, assim como outros imigrantes componentes do American Melting Pot (caldeirão americano), desempenham as funções que os americanos desprezam. Nas palavras do informante 10M:

Porque normalmente os trabalhos são períodos muito longo que você trabalha.

E você trabalha uns trabalhos que americanos não querem. Normalmente o que 
acaba sobrando é essas coisas de limpeza, é restaurante, e trabalho, principalmente em restaurante, a carga horária é muito grande [...].

O pessoal trabalha de às vezes dez da manhã à meianoite. E tem muita gente aqui que trabalha sete dias por semana e não seis dias.

Os tipos de trabalhos mais pesados, que envolvem algum tipo de insalubridade ou que não garantem um retorno financeiro expressivo são destinados à mão de obra estrangeira, mais barata e informal, na maioria das vezes. Digamos que a imigração faz "vista grossa" com os estrangeiros ilegais, usando-os como uma espécie de válvula de escape ou como reguladores naturais da empregabilidade americana. Quando falta emprego para os americanos, eles perseguem mais os estrangeiros, e quando a economia vai bem e os empregos abundam, eles esquecem os imigrantes por algum tempo.

Os brasileiros imigrantes se alimentam, sempre que possível, como no Brasil e vestem-se como no Brasil. Eles convivem entre si, tendo muito pouco contato com a cultura do país onde moram, exceto durante o trabalho, que normalmente não envolve comunicação oral significativa. Nas palavras do informante 10F: "Faço pão de queijo... Faço bolo, faço tudo. De vez em quando eu ainda faço, que tem cliente que pede pra fazer pão de queijo [...]”.

Como a língua é o modo, digamos, mais transparente de denunciarmos a nossa identidade, seria inevitável que essa língua sofresse alterações estando em contato com uma língua estrangeira, no caso, o inglês. Os brasileiros em questão, também popularmente conhecidos por "Brazucas", ao comunicarem-se entre si, fazem uso de inovações lexicais que mesclam inglês e português. Nesse processo, eles acabam criando um terceiro código que só é compreendido por falantes da sua comunidade de fala. Não é português, mas também não é inglês: para muitos é o "portuglês"ou "portinglês". É natural que, havendo duas ou mais formas de transmitir uma informação, configure-se aí um processo de variação linguística. Podemos dizer que concorre, então, uma forma de conflito com a forma "antiga", denominada "conservadora", sendo que a "inovadora" pode vir a substituir a "conservadora".

\section{Motivações para a pesquisa}

A primeira vez que me deparei com esse "Frankenstein" linguístico foi em 1990, em uma viagem de passeio aos EUA. De forma bastante natural, observei as pessoas dizendo que iam "parkear o carro" em certo lugar e que não podiam fazer certas coisas por estarem "bisados". Expressões como 
"parkear o carro" utilizam o conteúdo semântico do inglês (park=estacionar), acrescido da vogal temática "a" e a desinência de infinitivo " $r$ ", formando um verbo da primeira conjugação em português, em vez de dizerem "estacionar o carro". Já no outro exemplo de construção usada pelos brasileiros, a expressão "estou bisado" vem de busy, o adjetivo inglês para "ocupado" com a terminação do adjetivo e particípio passado "ado", do português. Como o recurso principal de que as línguas se servem para ampliar o léxico é a formação de palavras a partir de palavras/morfemas preexistentes, o ponto de partida para a criação de novas palavras é a utilização de uma "base" e o acréscimo de prefixos e sufixos, em um processo conhecido como derivação (SANDMANN, 1992, p. 23-24).

\section{Metodologia de pesquisa}

Com base nos postulados variacionistas de Labov, Weinreich e outros, realizei um estudo etnográfico constituído de entrevistas, questionários e listas de disponibilidade léxica com o objetivo de catalogar, compreender e explicar o uso dessas inovações lexicais. Um total de 30 informantes foram entrevistados com o propósito de definir as características sociodemográficas dos brasileiros usuários desse falar. Utilizando o teste Qui-quadrado, fizemos algumas descobertas bastante interessantes. Descobrimos, por exemplo, que a faixa etária, as atividades que os falantes desempenham naquele país, a idade de início da aprendizagem da língua-alvo, a sua proficiência na língua inglesa e o gênero têm papel importante nessas escolhas linguísticas.

Sabemos que dois falantes de uma mesma língua raramente se expressam do mesmo modo, assim como um mesmo falante nunca se expressa do mesmo modo em circunstâncias diferentes. Desse modo, a sociolinguística correlaciona as variações existentes na expressão verbal a diferenças de natureza social, classificando cada domínio, o linguístico e o social, como fenômenos estruturados e regulares, segundo Camacho (2003). A essas variações de natureza verbal e social dá-se o nome de variável linguística.

As inovações lexicais foram coletadas, contabilizadas, descritas e analisadas em termos de quem usa mais determinado tipo de inovação e por quê. Algumas perguntas de pesquisa relacionadas aos fatores que contribuem ou favorecem a criação e o uso dessas inovações lexicais e sintáticas nortearam esta pesquisa. 
As perguntas desta pesquisa foram as seguintes:

1) Quais são os fatores que contribuem ou favorecem a criação e o uso dessas inovações lexicais e sintáticas?

2) Como esse fenômeno pode ser caracterizado? Como "interlíngua"? Como "pidgin"? Como um estágio na evolução de aprendizagem de Língua Estrangeira?

3) Todos os brasileiros imigrantes se comportam do mesmo modo quanto ao uso dessas inovações lexicais?

4) Se há diferenças entre eles, quais são as condições, linguísticas e extralinguísticas, que favorecem e/ou inibem a mixagem observada?

Verificamos que os fatores que contribuem ou favorecem a criação e o uso das inovações estão ligados a algumas condições sociodemográficas dos usuários. Podemos, com base nas descobertas feitas até aqui, enumerar as características dos sujeitos-alvo desta pesquisa.

Dentre os brasileiros que estão nos Estados Unidos para trabalhar, mais de $50 \%$ desempenham atividade braçal, porém, mais de $40 \%$ desses brasileiros têm alto nível de proficiência em inglês. A maioria deles aprendeu inglês depois dos 21 anos e tem nível de escolaridade superior (43,3\%). Cerca de $80 \%$ dos informantes têm mais de 31 anos de idade e reside nos EUA há menos de dez anos. Esse é, portanto, o perfil de nosso informante.

Verificamos através da pesquisa que os usuários dessas inovações são, em geral, brasileiros de primeira geração, filhos de pais brasileiros que moram no Brasil, nascidos no Brasil, que foram para os Estados Unidos já adultos ainda sem terem competência linguística no idioma inglês. Esses brasileiros estão nos Estados Unidos com o objetivo de trabalhar e angariar fundos para investir em um futuro financeiro mais confortável no Brasil.

Vale lembrar, também, que a variedade linguística não padrão existente em nossa sociedade não é valorizada pela comunidade. $O$ falante que não domina a norma padrão culta, aquela valorizada socialmente, é visto como um transgressor da norma gramatical, inculto e pertencente a uma classe socialmente inferior. Isso parece explicar a estigmatização sofrida pela fala dos brasileiros nos EUA.

Além disso, o conceito de variável linguística pressupõe necessariamente que as duas ou mais variantes tenham o mesmo significado referencial ou valor de verdade, mas opostas em sua significação social e/ou estilística, pois 
os falantes não aceitam facilmente o fato de que duas expressões distintas signifiquem exatamente a mesma coisa, havendo forte tendência a atribuir-lhes significados diferentes. Isso se aplica sem maiores controvérsias a variáveis fonológicas. O mesmo não se pode afirmar sobre as outras variáveis, ou seja, em se tratando de variável morfossintática, por exemplo, fica difícil dizer quando duas ou mais estruturas expressam um único significado. Outro fator a se considerar é que um falante que domina a língua padrão - vista como aquela que possui maior prestígio social - em determinados momentos pode empregar a linguagem não padrão a fim de se aproximar de uma comunidade linguística que lhe desperta particular interesse. Logo, a variedade linguística que usamos frequentemente, nas mais diversas situações da vida, é fator de influência no comportamento social do indivíduo.

O que precisa ser considerado é que a língua padrão é só uma das variedades da língua, nem melhor e nem pior, do ponto de vista linguístico, sendo apenas mais uma variedade. Dessa forma, desprestigiar determinadas variedades linguísticas é perpetuar o preconceito linguístico.

\section{Língua e identidade}

O que realmente salta aos olhos em relação à mescla linguística realizada pelos brasileiros nos EUA é que ela é usada em situações específicas, com interlocutores próprios, como a demarcar um território e, dessa forma, evidenciar uma identidade. Segundo Le Page (1980), todo ato de fala é um ato de identidade. A linguagem é o índice da identidade por excelência. As escolhas linguísticas são processos inconscientes que o falante realiza e estão associadas às múltiplas dimensões constitutivas da identidade social e aos múltiplos papéis sociais que o usuário assume na comunidade de fala. $\mathrm{O}$ que determina a escolha de uma ou de outra variedade é a situação concreta de comunicação.

Para Tabouret-Keller, a língua falada por alguém e sua identidade como falante dessa língua são inseparáveis, sendo que "os atos linguísticos são atos identitários”, segundo Le Page e Tabouret-Keller (1985). Os gregos, por exemplo, identificavam como "não gregos" todos aqueles que soavam para eles como "barbarbar", denominando-os, então, "bárbaros". Em uma pesquisa realizada em 1978 em Belize, na América Central, ao ser perguntado como se reconhece um nativo de Belize, um deles respondeu que aquilo que o identificava era a língua que ele falava, pois poucos nativos falavam inglês ou espanhol, mas todos falavam "uma espécie de gíria" chamada crioulo. Po- 
demos inferir os dois significados do verbo “identificar” através desses dois relatos, segundo Tabouret-Keller. O primeiro ilustra a acepção de "identificar" tendo a língua como um comportamento externo permitindo a identificação de um falante como um membro pertencente a um grupo, como no caso dos "não gregos" identificados pelos gregos como estrangeiros pelo seu modo de falar. Já o segundo caso ilustra a acepção de "identificar" um nativo local através da língua que ele fala.

A identidade de uma pessoa é um conjunto heterogêneo composto de nomes atribuídos a ela e também adotados por ela. Durante o processo de uma vida inteira, entretanto, a identidade de um indivíduo é criada e recriada de acordo com as exigências sociais, interações com outros, desejos e outros fatores subjetivos e também muito particulares.

O que Tabouret-Keller chama de processos de identificação são os processos psicológicos através dos quais as identidades são criadas. A ligação entre língua e identidade é tão imbricada que basta um traço fonológico para identificar um indivíduo como membro do grupo, como aquela história bíblica do campo de batalha de Efraim. De acordo com essa história, os soldados usaram, para identificar os amigos em meio aos inimigos, um traço fonológico característico da língua dos amigos. Para isso, pediram que os soldados pronunciassem a palavra "shibboleth". Se o soldado pronunciasse / $\mathrm{s} /$ em vez de / / /, ele era identificado como inimigo e morto.

Os exemplos mencionados acima mostram como a identidade do indivíduo e a identidade social são mediadas pela língua: as características linguísticas são a ligação entre as identidades sociais e individuais, sendo que a língua oferece tanto um meio para ligar essas identidades quanto para expressá-las.

O objeto de nosso estudo é a fala dos brasileiros imigrantes nos EUA. Como muitos informantes declararam durante as entrevistas, é possível identificar um emigrante brasileiro apenas pelo seu jeito de falar. Esse processo de identificação do indivíduo pela sua fala é o que Tabouret-Keller chama de processos psicológicos através dos quais as identidades são criadas. Como os imigrantes brasileiros só usam esse linguajar entre si, esse falar tornou-se emblemático de sua situação socioeconômica nos EUA.

Como podemos perceber pelas observações feitas no parágrafo anterior, a língua estrangeira é um grande problema para os brasileiros no exterior. Segundo Sankoff (2001), podemos encontrar minorias linguísticas em todos os cantos do mundo, devido à imigração e também à adoção e, muitas 
vezes, imposição de línguas não faladas originalmente pela população local. Em muitos casos, isso resultou em perdas e em reduções da diversidade linguística, porém, o contato linguístico se tornou parte da vida de milhões de pessoas em todo o mundo.

Outra característica a ser mencionada é também o fato de uma escolha linguística ser "marcada" ou "não marcada". O modo esperado e "default" é o "não marcado"; qualquer coisa que seja diferente disso é "marcada". Assim como usar terno em plena praia de Copacabana ou contar piada de judeu em uma sinagoga, chamar as pessoas de "companheiros e companheiras", ou dizer que vai "parkear o carro" são escolhas "marcadas". A marcação é um conceito muito útil no sentido de que, uma vez identificada uma característica marcada, estaremos mais bem equipados para descrever a norma esperada.

Entretanto, isso não implica que essas normas sejam imutáveis. Há alguns anos, por exemplo, ver alguém falando sozinho na rua era um comportamento altamente "marcado". Hoje em dia, com o advento do celular, isso passou a ser lugar comum, comportamento "não marcado". O tempo muda os valores que atribuímos tanto a palavras quanto a fatos.

Os estudos sobre as propriedades do resultado de contatos linguísticos no discurso dos bilíngues são bastante complexos. Alguns itens podem ser emprestados de outra língua e nunca mais serem ouvidos, ou podem vir a ser usados com muita regularidade. Uma palavra pode seguir o padrão da língua materna ou da língua-alvo, dependendo da habilidade ou da intenção do falante e também de outros aspectos do contexto.

Esta pesquisa foi desenhada com o objetivo de conhecer e analisar o universo da fala dos brasileiros imigrantes nos EUA à luz da teoria variacionista de Labov. Foi um estudo de natureza exploratória, partindo de observações empíricas e chegando a conclusões de natureza científica, se considerarmos o estudo quantitativo e qualitativo realizado em torno do assunto - inovações lexicais realizadas por brasileiros nos Estados Unidos.

O presente estudo mostrou-se excelente oportunidade de observar a língua como produto da identidade social dos indivíduos. Sabemos que diferentes formas linguísticas servem para dizer a mesma coisa, porém, nunca imaginamos o quanto as escolhas lexicais do indivíduo podem torná-lo parte do grupo ou excluí-lo, assunto já aventado por vários autores, como Chambers (1993), Le Page e Tabouret-Keller (1985). 
O objetivo geral do presente trabalho era descrever as inovações lexicais encontradas entre brasileiros imigrantes nos Estados Unidos, correlacionando-as a fatores linguísticos e extralinguísticos.

Com esse propósito fizemos um alto investimento no sentido de investigarmos a fala desses brasileiros. Optamos pela investigação coletada a partir de dados empíricos feita in loco. Descobrimos um mundo onde brasileiros parecem viver em um universo paralelo, com regras de conduta próprias, cheio de estereótipos, histórias de vida incríveis, coisas que "só valem para lá”. As pessoas que estão nos Estados Unidos para trabalhar não agem como agiriam no Brasil. Os graus de latitude e longitude mudam, os valores parecem mudar com eles. - "A minha profissão no Brasil? Engenheiro... Aqui é 'bus-boy'?", que significa ajudante de garçom, profissão de menor status na escala de profissões dos Estados Unidos. Isso é a coisa mais comum de ouvir entre os brasileiros nos EUA. Há regras não escritas a serem seguidas e não estamos falando das leis americanas. É realmente um código de conduta que os brasileiros aprendem uns com os outros, em doses homeopáticas - quanto mais tempo se passa lá, mais se aprende sobre elas.

Não posso deixar de mencionar aqui que o fato de estar próxima àqueles brasileiros nos EUA foi o que me proporcionou muitas das inferências que seriam impossíveis de serem feitas se não vivesse como parte daquela outra dimensão. O contexto é muito importante quando se trata de estudos exploratórios.

Como não poderia deixar de ser, era necessário que houvesse uma língua que retratasse essa situação paralela e tão sui generis dos brasileiros nos EUA, já que a língua é emblemática em termos de identidade. Assim, com empréstimos aqui, mixagens ali e algumas traduções literais acolá, criou-se a língua que os brasileiros falam lá nos EUA. Se essa língua tem nome, não sei... Ouvi vários: Newarkês, Portuglês, Portinglês, mas preferi não rotular e simplesmente considerei esse "jeitinho brasileiro" de falar como "inovações lexicais" feitas no português de brasileiros moradores nos EUA.

As inovações lexicais foram coletadas, contabilizadas, descritas e analisadas em termos de quem usa mais determinado tipo de inovação e por quê. Algumas perguntas de pesquisa relacionadas aos fatores que contribuem ou favorecem a criação e o uso dessas inovações lexicais e sintáticas nortearam esta pesquisa. 
Pode-se dizer que 99\% dos entrevistados têm intenção de voltar ao Brasil para morar. Em geral, os usuários dessas inovações desempenham atividades manuais e informais nos EUA, sendo denominadas "labor" = trabalho braçal. Além das entrevistas, era muito comum ouvir na rua as pessoas dizerem que iam "ordenar" (de order = encomendar) um produto na fábrica, que iam "shopar" (de shop = fazer compras) naquela loja ou que estava "frizado" = freezing + gelado, já que a temperatura era de $-10^{\circ} \mathrm{C}$.

Dos 30 informantes da pesquisa, todos fizeram uso, em maior ou menor grau, de inovações lexicais. Dos quatro informantes (13,3\%) que fizeram uso reduzido dessas inovações, três estavam, de certa forma, fora das condições sociodemográficas estabelecidas acima: 4M, de 18 anos, era filho de brasileiros de classe trabalhadora e moradores nos EUA, porém nasceu nos EUA, sendo americano, ou segunda geração de brasileiros. Ele sempre frequentou a escola nos EUA e, portanto, fala inglês fluente, mas seu português deixa muito a desejar. Para Bills, Hudson e Chávez (1995), isso é consistente com a premissa do modelo linguístico descrito por Fishman (1966), Grosjean (1982) e Romaine (1995), segundo o qual a primeira geração de imigrantes permanece monolíngue em sua língua nativa, a segunda se torna altamente bilíngue e a terceira se torna dominante ou mesmo monolíngue na língua-alvo. $\mathrm{O}$ informante $4 \mathrm{M}$ passou um ano no Brasil, quando era ainda criança. Segundo o próprio informante, foi uma péssima experiência, pois ele não sabia português e teve enormes dificuldades na escola. Ao voltar para os EUA, foi colocado em uma série anterior, o que parece ter sido bastante traumatizante para ele. Esse informante respondeu cerca de 70\% da entrevista completamente em inglês. No caso desse informante, as inovações lexicais ocorreram no sentido inverso. O português acabou influenciando o seu inglês. $\mathrm{O}$ informante declarou usar expressões como face no lugar da interjeição "cara" e foi ridicularizado pelos colegas brasileiros por isso. Outro exemplo de influência do português no inglês foi quando ele perguntou à mãe: “Are you on?", referindo-se à gíria comum entre os jovens brasileiros: Tá ligado?”. Observamos que $4 \mathrm{M}$ fez uso de inovações lexicais no sentido inverso àquele investigado por esta pesquisa. Em ambos os casos, ocorreram calques fonologicamente independentes, com traduções literais do português para o inglês, usando-se palavras que não guardam semelhança fonológica entre si, como em cara = face e ligado = to be on.

Já o informante $5 \mathrm{M}$ foi para os EUA com apenas 7 anos de idade e sempre frequentou a escola nos EUA, sendo, portanto, um bilíngue perfeito, es- 
tando, agora, com 29 anos de idade. Além disso, 5M formou-se em administração nos EUA e atua como administrador em uma empresa americana tendo um emprego almejado até por americanos, com um bom salário e estabilidade financeira. O sonho dele é, entretanto, conseguir um emprego no Brasil e se mudar prá cá com sua esposa brasileira.

A informante 9F é uma brasileira de segunda geração, nascida nos EUA, cujos pais, separados, vivem nos EUA, o pai na Flórida e a mãe com ela em New York. Ela é falante nativa de inglês e sua competência comunicativa em português é também muito boa. Os desvios cometidos por ela poderiam ser cometidos por qualquer pré-adolescente de 12 anos que se aventurasse a dizer palavras um pouco mais sofisticadas sem muito conhecimento de causa sobre o assunto. Ela teve problemas com palavras como "depressionada" significando "depressiva" e "obsessiva" significando "obcecada”. Ela se interessa por línguas estrangeiras e está também aprendendo chinês na escola.

Já a informante $10 \mathrm{~F}$ é uma mulher de meia idade, mãe de família, que deixou os filhos no Brasil em busca de melhores condições de vida para criá-los no Brasil, mesmo estando nos EUA. Ela foi a única do grupo de inovações reduzidas que se encaixava perfeitamente no perfil dos usuários das inovações, embora não as tivesse utilizado durante a entrevista. Mesmo depois de cinco anos morando naquele país, $10 \mathrm{~F}$ não parece se interessar por nada que se relacione aos Estados Unidos ou à língua falada por lá. Ela trabalha como manicure em um salão de beleza de brasileiros para brasileiros. A impressão que se tem é que ela rejeita tudo que a lembre de sua condição de estar ali, contra a sua vontade, longe dos filhos, com o objetivo de ganhar dinheiro e de comprar uma casa.

Os restantes 26 informantes brasileiros, mesmo quando não fizeram uso explícito das inovações lexicais, demonstraram claro conhecimento sobre elas, seu significado e a razão de seu uso e vasta difusão. Todos os 26 informantes são brasileiros de primeira geração, falam português fluentemente, todos trabalham ou estudam nos EUA e a maioria deles desempenha atividades consideradas trabalhos braçais.

A segunda pergunta foi em relação ao fenômeno a ser caracterizado:

Como esse fenômeno pode ser caracterizado? Como "pidgin"? Como "interlíngua”, um estágio na evolução de aprendizagem de Língua Estrangeira? O meu propósito era então, taxonômico, pois havia necessidade de encaixar esse fenômeno em algum fenômeno já descrito pela linguística. "Pidgin”, in- 
terlíngua, estágio na evolução da aprendizagem de língua estrangeira pareciam opções interessantes naquele momento.

$\mathrm{Na}$ falta de um termo mais adequado, adotamos o termo "inovação lexical” para evitar rótulos. Sabemos, entretanto, que não se trata de interlíngua, termo segundo o qual um falante aprendiz de língua estrangeira, ou de segunda língua, engaja em uma jornada linguística de sua língua nativa para a língua-alvo e constrói naturalmente um sistema linguístico particular nesse "meio tempo", ou "interim time".

A teoria da interlíngua é muito importante no processo de Aquisição de Segunda Língua porque foi a primeira a tentar explicar esse processo sem contradizer a hipótese do período crítico para aquisição de segunda língua. Além disso, buscava explicações para o fato de que a maioria dos falantes não adquirem competência plena em língua estrangeira, um problema que continua incomodando linguistas e professores de línguas em toda parte.

Como podemos verificar, a primeira parte da pergunta e a terceira se sobrepõem, já que a interlíngua pode ser considerada um estágio de aprendizagem da língua estrangeira. Não parece ser o caso da fala dos brasileiros nos EUA. Os brasileiros fazem uso sistemático dessas inovações, mesmo quando já falam inglês fluente, mas estão falando com outros brasileiros.

A segunda parte da pergunta, porém, menciona o "pidgin", que vem a ser uma linguagem de vocabulário limitado e de gramática simplificada utilizada para permitir a comunicação de grupos que não falam a mesma língua. Quando um "pidgin” se estabelece como língua nativa de uma comunidade linguística, ele se torna um "crioulo".

Nesse caso, as próprias definições de "pidgin" e de "crioulo" respondem à pergunta. Já que essa modalidade de linguagem serve para permitir comunicação de falantes de línguas diferentes, essa definição não se encaixa nas inovações lexicais realizadas pelos brasileiros nos EUA, pois todos são falantes de português brasileiro como língua materna.

Rótulos como "dialeto", "pidgin" e "interlanguage" são, portanto, inadequados para explicar a ocorrência dessas variações características da fala dos brasileiros nos EUA.

Buscando elucidar a questão, podemos caracterizar a fala dos brasileiros imigrantes nos EUA como um português repleto de inovações lexicais que geralmente resultam de línguas em contato.

A terceira pergunta tinha relação com o comportamento linguístico dos brasileiros em questão e as condições linguísticas e extralinguísticas favorá- 
veis ou desfavoráveis à mixagem observada: "Todos os brasileiros imigrantes se comportam do mesmo modo quanto ao uso dessas inovações lexicais? Se há diferenças entre eles, quais são as condições, linguísticas e extralinguísticas, que favorecem e/ou inibem a mixagem observada?"

Tendo em mente a parte quantitativa aqui desenvolvida, podemos responder a essa pergunta, agora com dados mais realistas e sem a atitude puramente intuitiva que marcou o início deste trabalho.

Como pudemos observar no decorrer desta pesquisa, os brasileiros imigrantes alvos de nosso estudo se comportam, no que concerne ao uso e à difusão das inovações lexicais, de formas diferentes, motivadas por condições sociodemográficas diferentes.

Os informantes participantes desta pesquisa, entretanto, eram, em sua maioria, brasileiros de primeira geração, ou seja, nascidos no Brasil, e que se mudaram para os Estados Unidos depois dos 31 anos de idade, ainda sem saber falar inglês. O objetivo primordial desses brasileiros não era aprender inglês, conhecer uma nova cultura ou fazer turismo no exterior. O objetivo de todos eles era trabalhar e ganhar dinheiro para voltar ao Brasil, comprar imóveis e viver no Brasil pelo resto da vida.

Em relação aos tipos de inovações lexicais mais usados pelos informantes, podemos dizer que a maioria dos brasileiros usa pelo menos um tipo de inovação: o empréstimo linguístico. Esse tipo de inovação costuma ser classificado como empréstimo para comunidades linguísticas que mantêm a sua língua materna e como substrato caso a língua seja trocada por outra. O motivo do aparecimento desse fenômeno é bastante óbvio. Emprestam-se termos que não estão disponíveis na língua de origem, nesse caso, o português, por alguma razão. As razões dessa indisponibilidade podem ser caracterizadas como a aparição de novos conceitos oriundos da língua-alvo ou a busca de adequação terminológica. Seria muito difícil conseguirmos um termo mais adequado do que "marketing" para expressar essa ideia, por exemplo. O termo em português existe, é "mercadologia”, mas não tem o alcance semântico do termo em inglês.

\section{Conclusões}

Baseando nossa pesquisa em Otheguy e Garcia (1988), observamos o tipo de inovações lexicais recorrentes na fala dos informantes desta pesquisa. É natural que o contato entre os vários idiomas do mundo tenha provocado o surgimento de dois fenômenos linguísticos, o estrangeirismo e o emprésti- 
mo. No senso comum, emprestar é confiar algo a alguém por algum tempo, com promessa de restituição. Não é, com certeza, o caso dos empréstimos linguísticos, que nunca são restituídos. A diferença básica entre os dois é que o estrangeirismo, além de ser uma palavra emprestada de outra língua, sofre mudanças morfológicas e fonológicas na língua recipiente, como seria o caso do "deletar". Em termos de adaptação fonológica, um exemplo seria o fonema [r] retroflexo em "parkear", que é pronunciado como [h], em uma aproximação com a pronúncia do português do Brasil.

Já o empréstimo não sofre alterações morfológicas, sendo usado com a forma fonológica mais próxima possível da língua-alvo, caso do comumente utilizado "delivery".

Em segundo lugar, observamos os calques fonologicamente mixados. As condições linguísticas que parecem favorecer esse tipo de inovação lexical são a proximidade fonológica e morfológica entre os termos, como em "aplicar" e "apply" e o fato de o termo não ser do conhecimento do indivíduo em sua língua nativa, como em "vaquear" = usar aspirador de pó ou "mopear" = usar o esfregão. Como exemplo de calques fonologicamente mixados, temos "acento" = sotaque e "printar" = imprimir.

Em terceiro lugar, foram observados os calques frasais, como "ele é suposto de fazer isso". Já em quarto lugar ficaram os calques independentes fonologicamente, como em "vou caminhar o cachorro". Tanto os calques frasais quanto os calques fonologicamente independentes ocorreram nas entrevistas, porém, com frequência insignificante em relação ao universo de inovações lexicais. Entretanto, podemos traçar o perfil do usuário dessas inovações lexicais.

A motivação linguística para o uso de calques fonologicamente independentes está na analogia feita pelo falante no nível do significado e não do significante. Não há nenhuma semelhança fonológica ou morfológica do termo na língua materna com o termo na língua-alvo. A conexão entre eles está sendo feita apenas no nível semântico: "correu" para presidente = concorreu à vaga de presidente (ran for president); "jogar" uma festa = dar uma festa (throw a party); Vou "caminhar" o cachorro = levar o cachorro pra passear (walk the dog); "Ele é suposto de ir" = (ele deve ir) para (He is supposed to go).

A motivação linguística para o uso desse tipo de inovação reside no fato de que o falante deseja expressar uma ideia da língua-alvo que não está disponível na língua materna. Um bom exemplo de calque frasal é: "Me deixe saber!" (Mantenha-me informado) oriundo de "let me know", expressão muito usada em inglês e que o brasileiro adota em "português". 
A pergunta 4: Se há diferenças entre eles, quais são as condições, linguísticas e extralinguísticas, que favorecem e/ou inibem a mixagem observada?

Os dados obtidos através desta pesquisa sugerem que as condições linguísticas que favorecem as inovações lexicais são, em primeiro lugar, o fato de ser uma palavra de conteúdo e, em segundo lugar, a classe de palavras em que incide a inovação.

Já as condições extralinguísticas que favorecem o uso de inovações lexicais são a idade, tempo que os indivíduos passam nos EUA, nível de escolaridade, nível de proficiência em língua inglesa, início da aprendizagem de língua estrangeira e o tipo de atividade exercida pelos informantes nos EUA.

Verificamos, através dos dados, que as palavras de conteúdo usadas nas inovações são, em larga escala, substantivos, verbos e adjetivos, nessa ordem. As inovações lexicais que tiveram mais ocorrência em nossos dados foram os empréstimos linguísticos, constituídos, em sua maioria, de substantivos. Os informantes que fizeram maior uso de empréstimos foram os jovens adultos, de menos de 30 anos de idade, com tempo de residência de menos de 20 anos nos EUA, de nível de escolaridade média ou superior, nível alto de proficiência da língua inglesa, iniciando sua aprendizagem de inglês antes dos 20 anos e representantes da mão de obra braçal nos EUA.

Em segundo lugar, detectamos a ocorrência de calques mixados, constituídos, em sua maioria, de verbos. Os informantes que fizeram maior uso de calques mixados foram adultos de mais de 31 anos de idade, com menos de dez anos de residência nos EUA, com nível fundamental de escolaridade, nível baixo de proficiência de língua inglesa, que iniciaram a aprendizagem de língua inglesa após os 21 anos de idade e que são representantes da mão de obra braçal.

Detectamos uma maior incidência de inovações lexicais em determinados campos semânticos como "Atividades desempenhadas pelos informantes nos EUA" e "Eletrodomésticos", porém, ao verificarmos se o campo semântico influenciaria o tipo de inovação lexical a ser utilizado pelo informante, constatamos, através do teste Qui-quadrado, que essas variáveis não guardam correlação, o que foi uma surpresa para nós, que tínhamos expectativa de que, ao falar sobre as suas atividades nos EUA, os informantes fizessem mais uso de calques mixados, o que, contudo, não se confirmou.

Como as classes de palavras saltam aos olhos do pesquisador desse tipo de dados, decidimos verificar uma possível correlação entre as classes de pa- 
lavras e os tipos de inovações lexicais detectadas em nosso corpus. Sabemos que algumas classes de palavras são mais propícias a alguns tipos de inovações lexicais, como é o caso dos substantivos face aos empréstimos linguísticos, plenamente documentados neste trabalho. Em nosso corpus, os substantivos ocorreram em frequência superior ao esperado em respeito aos empréstimos linguísticos e inferior em respeito aos calques mixados, ilustrando a hipótese de que os substantivos se prestam mais a empréstimos linguísticos e menos a calques mixados.

Os verbos, por sua vez, ocorreram em frequência muito superior ao esperado nos calques mixados, revelando aquilo que realmente pode ser chamado de inovação lexical, que realmente opera alterações nos vocábulos da língua recipiente e da língua doadora, como o acréscimo de afixos, desinências, vogais temáticas, que mostram a criatividade do informante no manuseio de dois códigos linguísticos, estão concentradas nos calques mixados, mais especificamente nos sintagmas verbais. Não é de estranhar que isso ocorresse, já que o nosso informante é um ser agente por natureza, que se encontra nos EUA para agir, trabalhar, "mopar", "vaquear" e, por que não, "parkear".

Essa conclusão tem respaldo também na pesquisa de Poplack, Sankoff e Miller (1988), que afirmam que, embora todas as palavras de conteúdo se encaixem na categoria "adequadas para empréstimo", especialmente os substantivos e algumas outras classes de palavras, como verbos, adjetivos e advérbios, apenas alguns itens são recorrentes, sendo que apenas um conjunto mais restrito é usado pelos monolíngues ou pelos bilíngues com pouca fluência em inglês.

O português dos brasileiros imigrantes nos Estados Unidos apresenta evidências consideráveis de penetração lexical de inglês. Essa influência pode ser considerada um tipo de adaptação linguística criativa por parte de uma comunidade que aparentemente deseja continuar comunicando, em sua língua materna, mensagens que são características da cultura de língua inglesa.

Em relação à motivação para a ocorrência dessas inovações lexicais, nossa pesquisa confirma a afirmativa de Otheguy e Garcia (1988) de que o falante de uma minoria linguística tem duas necessidades básicas conflitantes: falar a sua língua nativa e comunicar ideias, noções e mensagens que não estão disponíveis em sua língua materna, mas que são de repertório corriqueiro na língua-alvo. Essa afirmativa, aliás, já havia sido sugerida por Haugen, em 1938. 
A nossa pesquisa confirma também algumas descobertas feitas por Poplack, Sankoff e Miller (1988). A proficiência em duas línguas tem um efeito sistemático no uso de inovações lexicais, já que é o conhecimento de ambas as línguas que pressupõe o uso de estratégias de formação de novas palavras, conhecidas também por $=$ nonce borrowings. Entretanto, as normas da comunidade de fala superam em muito as habilidades individuais. Caso o indivíduo resida em uma área em que todos os membros se dirijam uns aos outros fazendo uso das inovações lexicais, naturalmente elas serão usadas pelo indivíduo, segundo a Teoria da Acomodação de Giles (1980). Essa descoberta, relatada pela primeira vez por Poplack, Sankoff e Miller (1988), e ratificada pela presente pesquisa, nos mostra que o comportamento em relação ao uso de inovações lexicais é adquirido, não sendo apenas uma questão de necessidade lexical. Se não fosse assim, a capacidade individual seria mais importante que o contato que ele tem com a sua comunidade de fala. Em vez disso, tanto os padrões de uso de empréstimos quanto à quantidade de inovações utilizadas parecem corresponder a normas ambientais mais abrangentes, evidenciadas por estigmatizações em relação ao uso dessas inovações ou simplesmente por uma tendência da comunidade de usar um padrão particular de inovações lexicais.

A questão da identidade em relação ao uso das inovações lexicais pode ser evidenciada considerando-se que o indivíduo em questão tem, nos seus pares nos EUA, a única esperança de sobrevivência naquele país. A possibilidade que um imigrante ilegal tem de conseguir um emprego, por exemplo, é ter um "canal" informal que o leve até esse emprego. Esse "canal" é representado pelos novos "amigos de infância" que os imigrantes fazem ao chegarem aos EUA. Isso não acontece apenas em relação ao trabalho. Conseguir moradia, saber onde arranjar móveis de forma mais econômica, a forma mais barata de ligar para o Brasil... São tantos detalhes que somente outro brasileiro em situação semelhante poderia ajudar. Se a comunidade fala dessa maneira, fazendo um uso arraigado de inovações lexicais, todo novo imigrante tende a perpetuar esse uso das inovações lexicais, tornando-se parte do grupo. Por isso, o uso de inovações lexicais parece ser tão emblemático em relação aos seus usuários.

Como pudemos verificar até mesmo através das entrevistas, os indivíduos estão interessados na comunicação rápida e eficiente de mensagens que são relevantes à sociedade em que estão inseridos, não relutando em introduzir itens lexicais e conceitos que são respaldados pelos seus pares, elimi- 
nando-os quando eles criam ambiguidades. Isso também confirma as afirmativas de Otheguy e Garcia (1988).

As situações de contato linguístico parecem estar sujeitas a dois tipos de forças conflitantes: a necessidade de atingir eficiência comunicativa para conseguir interação e a necessidade de preservar a distinção de identidade de grupo. Se a maioria dos falantes de português brasileiro nos Estados Unidos, na situação social determinada anteriormente, fala "vou 'parkear' o carro" e não "vou estacionar o carro", tendemos a inferir, com base nos postulados da sociolinguística, que não se trata de um fenômeno aleatório de uso arbitrário e inconsequente dos falantes, mas, sim, do uso sistemático e regular da variação linguística. É exatamente essa regularidade e sistematicidade que buscamos demonstrar com o presente trabalho.

\section{Referências Bibliográficas}

BILLS, Garland; CHÁVEZ, E. Hernández; HUDSON, Alan. The geography of language shift: distance from the Mexican border and Spanish language claiming in the southwestern United States. International Journal of the Sociology of Language, n.114, 9-27, 1995.

BORTONI-RICARDO, S. M. The urbanisation of rural dialect speakers: A sociolinguistic study in Brazil. Cambridge; New York: Cambridge University Press, 1985.

CAMACHO, Roberto Gomes. Sociolinguística. In: MUSSALIM, F.; BENTES, A. C. (Org.). Introdução à linguística; domínios e fronteiras. 3. ed. São Paulo: Cortez, 2003. p. 49-75. v.1.

CHAMBERS, J.K. Sociolinguistic Theory: linguistic variation and its social significance. Oxford: Blackwell Publishers, 1995.

. Sociolinguistic theory. 2nd ed. Oxford: Blackwell, 2003.

GILES, H.; JOHNSON, P. International Journal of the Sociology of Language. v. 1987, issue 68, p. 69-100, 1987.

GROSJEAN, François. Life with two languages. Cambridge: Harvard University Press, 1982.

HAUGEN, E. Language and immigration. In: DIL, Anwar S. (Ed.). The ecology of language: Essays by Einar Haugen. Stanford: Stanford University Press, 1938, reprinted 1972. p. 1-36. 
LEPAGE, R. B. Hugo Schuchardt's Creole Studies and the problem of linguistic continua. In: K. LICHEM; SIMON, H. J. (Ed.). Hugo Schuchardt: Schuchardt Symposium, 1977. Graz: 1980.

OTHEGUY, Ricardo; GARCÍA, Ofelia. Diffusion of lexical innovations in the Spanish of Cuban Americans. 1988.

POPLACK, S.; SANKOFF, D.; MILLER, C. The social correlates and linguistic processes of lexical borrowing and assimilation. Linguistics 26, 1.47-104, 1988.

POTTIER, B. La situation linguistique en France. In: MARTINET, A.; ROMAINE, S. Language in society: an introduction to sociolinguistics. London: Blackwell, 1994.

SANDMANN, A. Morfologia lexical. São Paulo: Contexto, 1992.

SANKOFF, G. Multilingualism in Papua New Guinea. In: SANKOFF, G. The Social Life of Language. Philadelphia: University of Pennsylvania Press, 1980. p. 95-132.

TABOURET-KELLER, A. Language and identity. In: COULMAS, F. (Ed.) The handbook of sociolinguistis. Blackwell: London, 1998.

WEINREICH, U.; LABOV, W.; HERZOG, M. Empirical foundations for a theory of language change. Directions for historical linguistics. In: W. Lehmann; Y. Malkiel (Ed.). Austin: University of Texas Press, 1968. p. 95-195. 